\title{
El Registro de Vecindad del Partido de Patagones (1887) y los niños indígenas como botín de guerra
}

The Registro de Vecindad of Patagones area (1887) and indigenous children as spoils of war

Jorge A. Bustos, and Leonardo A. Dam

\section{(2) OpenEdition}

\section{Journals}

\section{Electronic version}

URL: http://journals.openedition.org/corpusarchivos/1005

DOI: 10.4000/corpusarchivos. 1005

ISSN: $1853-8037$

\section{Publisher}

Diego Escolar

\section{Electronic reference}

Jorge A. Bustos, y Leonardo A. Dam, «El Registro de Vecindad del Partido de Patagones (1887) y los niños indígenas como botín de guerra », Corpus [En línea], Vol 2, No 1 | 2012, Publicado el 30 junio 2012, consultado el 20 abril 2019. URL : http://journals.openedition.org/corpusarchivos/1005 ; DOI : 10.4000/corpusarchivos.1005

This text was automatically generated on 20 April 2019. 


\section{El Registro de Vecindad del Partido de Patagones (1887) y los niños indígenas como botín de guerra}

The Registro de Vecindad of Patagones area (1887) and indigenous children as spoils of war

Jorge A. Bustos, and Leonardo A. Dam

\section{EDITOR'S NOTE}

Fecha de recepción del original: 15/05/2012. Fecha de aceptación para publicación:

$18 / 06 / 2012$

1 Un sector del archivo histórico del museo guarda documentación en distintos grados de organización, rescatada de diversos organismos oficiales por Emma Nozzi, nuestra anterior directora, cuando el destino de esa documentación era la incineración o la continuidad de su degradación ${ }^{1}$. Recientemente, el equipo de historiadores y técnicos del museo hemos iniciado el ordenamiento de las cédulas de los "registros de vecindad" de varios años, las que se hallaban mezcladas. El primer paso fue organizar las correspondientes al registro de 1887 , que cuenta con un total de cuatrocientas cincuenta y cinco cédulas. Aquí se reproduce una de ellas en versión facsimilar, que lleva la planilla de datos de los registrados en cada vivienda en el anverso, mientras que en el reverso da cuenta del marco legal que ordenaba el registro (figs. 1 y 2). La tarea fue dificultosa ya que pocas de estas cédulas habían sido fechadas. Nos hemos valido entonces, entre otros recursos, de algunas dataciones asentadas esporádicamente por los vecinos, de las distintas calidades del papel y de la reconstrucción de los circuitos de los censistas, calle por calle de Patagones. Si bien presumimos que faltan algunas cédulas del Cuartel 1 (urbano), creemos que en todo caso las faltantes serían escasas, considerando la cantidad de habitantes de ese distrito que arrojan los censos de 1881 y 1895. En cambio, 
presumimos que es posible que en el caso de los cuarteles rurales el faltante sea algo mayor.

El Registro de Vecindad fue creado por la ley orgánica de las municipalidades de 1876 para la ciudad de Buenos Aires, pero ignoramos en qué año se dispuso implementarlo en el resto del territorio provincial. Sí sabemos que avanzada la década de 1880 debía ser hecho cada dos años en todos los partidos bonaerenses. A cada unidad de vivienda le correspondía una planilla o cédula dividida en dos cuerpos horizontales, tal como puede verse en el facsímil del documento anexo. En el cuerpo superior se volcaban el nombre del propietario de la casa o del inquilino principal, la calle y número y el cuartel. En el cuerpo inferior se consignaban los datos de quienes vivían en el inmueble: nombre y apellido, edad, sexo, estado civil, nacionalidad, profesión u ocupación (en el caso de los niños, si asistían o no a la escuela), si sabía leer o escribir y un espacio libre para las observaciones.

De los 2.733 habitantes que figuran en el Registro de Vecindad, 2.019 son urbanos y 714 rurales. De ese universo fueron consignados en la categoría "indio", "india" o "china" 130 personas, de las que 104 (80\%) son menores de edad. De esos "indios" menores de edad, 97 $(93,26 \%)$ están registrados en casas de familias criollas o de origen inmigrante, mientras que los siete niños restantes (6,73\%) viven en el seno de familias que eran consideradas indígenas. Cabe señalar que de los 130 "indios" que figuran en el Registro, sólo 15 son pobladores rurales, mientras los restantes 115 son urbanos.

Que el registro no es exhaustivo lo prueban cinco niños indígenas que hemos identificado en los libros de la Defensoría de Menores del Partido y que no aparecen en aquel ${ }^{2}$. Si además contrastamos la información del registro con los asientos de bautismos, matrimonios y defunciones de los libros de la Parroquia de Carmen de Patagones, las diferencias se hacen más notorias aún.

5 En una rápida mirada del registro, los veintiséis adultos registrados como "indio", "india" o "china", resultan muy pocos, habida cuenta de que el proceso de inserción urbana de indígenas en Patagones se verifica desde fines del siglo XVIII y continúa a lo largo del siglo XIX en un proceso que para sus primeras décadas ha sido convenientemente analizado por Geraldine Davies ${ }^{3}$. La respuesta contundente la tuvimos con el "Censo poblacional de 1886 del departamento Viedma". Allí vemos, por caso, que tanto el cacique y sargento mayor Miguel Linares como su gente del paraje San Gabriel, tierra adentro a tres leguas de la capital de la Gobernación, han sido asentados como "argentinos".

6 Es decir que para los censistas, los "indios" son los naturales que eran clasificados mediante criterios culturales imprecisos, pero que respondían en lo fundamental al mayor o menor grado de autonomía en relación al Estado que tuvieran los individuos y las poblaciones que eran calificadas así. Tal como se plantea en los trabajos de Diego Escolar, "indígena" es principalmente una categoría política. Podemos colegir entonces que los "indios" del registro de 1887 han arribado en tiempos relativamente recientes a la aldea de Carmen de Patagones. La mayoría son aquellos niños que los registros parroquiales nos muestran como "hijo de padres indios desconocidos", aunque sus páginas se agiten aún por los gritos desgarradores de las madres despojadas de su ser más preciado.

7 No se debe descartar la circunstancia de que eran actores diferentes los que debían estampar el "indio" o "china" en la documentación, distintas las subjetividades y los criterios institucionales aplicados. Incluso la relevancia social del censado podía evitarle 
el mote a una persona apreciada. Por caso, el censista de la zona de San Gabriel era, precisamente, Miguel Linares, quien posiblemente haya diferido con la perspectiva de quienes tuvieron la tarea en Carmen de Patagones.

8 Otro aspecto a destacar es el de la educación de estos niños y jóvenes. Al respecto observamos una actitud diferencial de los adultos tenedores de indígenas, no ya respecto de sus propios hijos, sino en relación a otros niños incorporados a las familias como es el caso de los huérfanos criollos. Claramente, en la mayoría de los casos, las familias receptoras se desentienden de la escolaridad de los niños indios. Y esto se hace notorio cuando sus hijos e incluso los huérfanos bajo su tutela asentados como "argentinos", sí iban a la escuela 5 . De 83 niños indígenas, domiciliados en Carmen de Patagones en edad escolar (4 a 16 años), solo el 19,27\% concurre a la escuela ${ }^{6}$. Mientras que para los niños "argentinos", para la misma franja etaria, de 599 concurren a la escuela 293 es decir un $48,91 \%$. Estos guarismos tienen el agravante de que los niños indios no se encontraban en hogares pobres de criollos o inmigrantes europeos cargados de hijos donde ninguno tenía la posibilidad de concurrir a establecimientos educativos, sino que se encontraban en las familias más destacadas de la aldea, la totalidad de cuyos hijos estaba escolarizada ${ }^{7}$. Se da por ejemplo el caso de la familia del militar Segundo Molina que tiene cinco hijos de los cuales tres están en edad escolar y concurren a la escuela, además hay cinco jóvenes indígenas de los cuales tres están en edad escolar pero ninguno de ellos va a la escuela y solo uno sabe leer.

9 Desconocemos la razón por la cual en este registro de vecindad se consignó a los "indios". Presumimos que puede deberse a una requisitoria del Defensor de Menores del Partido que en esos años pugnaba, con escaso éxito, por elaborar un censo de menores huérfanos que reflejara con cierta exactitud la situación de Carmen de Patagones en la materia. El interés que en nosotros concitó esta cuestión no debería oscurecer otros aspectos significativos del registro que podrían servir para alumbrar otras indagaciones. Es el caso, por ejemplo, del proceso de ruralización que se había iniciado en la década de 1880 .

10 Finalmente, cabe consignar que esta fuente se convirtió en disparador de una investigación que estamos realizando desde el museo sobre la cuestión de la distribución de niños indígenas en Patagones durante las campañas militares a partir de 1878, y las acciones que la Iglesia y el Estado emprendieron para su resguardo. Así, transcribimos una esquela a Lino De Roa, comandante de la columna que persiguió a las familias de Sayhueque, Foyel, Inacayal y otros grandes jefes por el interior de Río Negro y Chubut, anexando estos territorios para la nación:

11 Amigo Roa, necesito que me haga el servicio de separarme dos chinitas buenas de las que trae y que ya el General Vintter sabe sobre esto, y le agradecería si pudiera mandármelas en la primera oportunidad, estas chinitas son para mi familia. También le encargo cualesquier curiosidad que pueda encontrar en duplicado pues estoy arreglando una pequeña colección y desearía obtener algo de por esos parajes ${ }^{8}$.

12 Peticiones como la precedente eran habituales en el Carmen de Patagones y Viedma de la primera mitad de la década de 1880 . Ninguna de ellas contempla una fórmula especial, ni brinda justificación o compromiso alguno respecto de la criatura que se solicitaba. Todas redactadas en un simple papel sin mucha caligrafía ni estilo. Esta investigación nos permitió saber que no se precisaba más para hacerse de un niño o niña indígenas, igualados con "cualquier curiosidad" duplicada que pudiera agregarse a una colección de rarezas naturales o arqueológicas de los territorios sobre los cuales se expandía el Estadonación. 
13 Como se dijo, la recuperación reciente del Registro de Vecindad de 1887 mostró un número significativo de "indios". Y que de ellos, la inmensa mayoría son niños y adolescentes que viven en casa de vecinos criollos o de origen europeo. Nuestra decisión de abordar la investigación se vio facilitada porque en el archivo del museo disponíamos de otras fuentes primarias, además del citado registro, en las que, como supusimos, encontraríamos respuesta a las preguntas que se nos planteaban. Así nos apoyamos en los libros parroquiales de bautismos y defunciones, en la documentación de la caja Militar ${ }^{9}$, en los libros de la Defensoría de Menores, en los expedientes del Archivo Histórico del Juzgado de Paz y en el Registro de Fuentes Orales del museo ${ }^{10}$.

14 Con este trabajo en curso nos proponemos demostrar, entonces, que los niños de las familias indias desestructuradas por el ejército de Roca y asignadas a vecinos de Patagones, lejos de nuestra inicial suposición, no contaron con ningún tipo de salvaguarda por parte de los salesianos arribados al Carmen desde 1880 (fig. 3). En la extensa lista de asuntos que requirió el intenso accionar de la orden religiosa, no hubo sitio para el cuidado de la seguridad física de estas criaturas y mucho menos para su educación. En cambio, nos sorprendió que el Estado desplegara, en la segunda mitad de la década de 1880, algunos dispositivos institucionales que atendían a los niños desvalidos, es decir criollos huérfanos e indios entregados a las familias pudientes. Si bien algunos de estos nuevos arbitrios tuvieron un alcance limitado o no cumplieron cabalmente su 
misión, ello obedeció más a la connivencia de funcionarios y vecinos con huérfanos o indios a cargo, que a debilidades o falencias de normas e instituciones. 


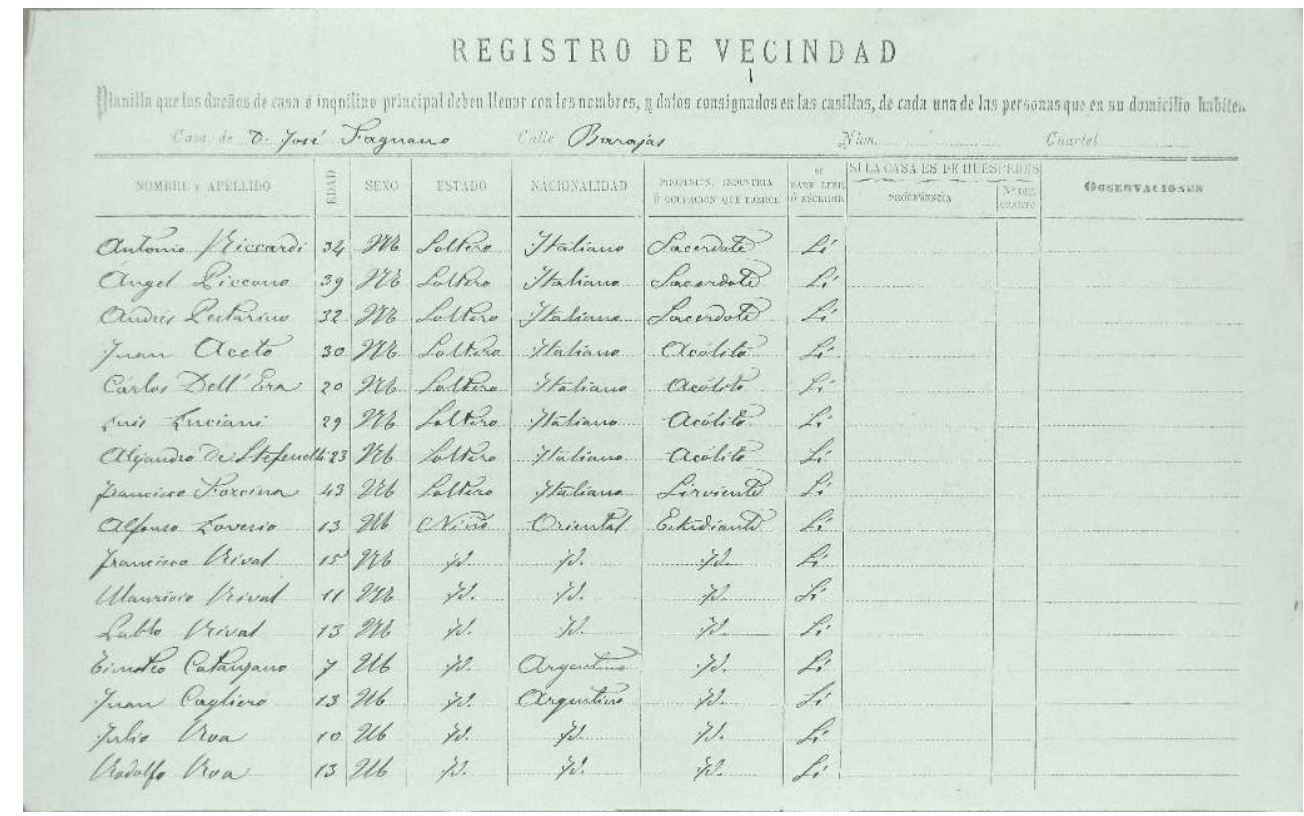

FIgURA 1: PLANILLA DEL REgIStRo de VECINDAd (1887), CASA dE dON JOSÉ FAgNANO

Art. 46. El Registro de recindad hospitales, casas de asistencia ú hoscomprendera todos los habitantes del pedaje, estan obligados a dar a la musicipio, con designacion de las ca- Municipalidad la declaracion corressas que habitan, sus nombres, edad. sexu, estado, nacionalidad, profesion, industria u ocupacion y si sabe ler. 0 escribir.

Este Registro se renovará cado dos años sin periuicio de las rectificaciones que en el tiempo intermedio pudieran hacerse de oficio ó à instancia de parte.

Art. 47. Los vecinos que cambiaren de domicilio, los que ingresen en el municipio, los padres de los recien nacidos, los administracores de casas de expósitos, los parientes de los fimados, ó el dueño de casa, a falta de aquellos, asi como los encargados do pondiente, dentro de las cuarenta y ocho horas de ourrida la defuncion, el nacimiento ó el eambio de domicilio para que se haga la anctacion correspondiente en el Registro.

El término de cuarenta y ocho horas se ampliará con un dia mas por cada dos leguas, ciando la persona que deba prestar la declaracion resida fuera del pueblo cabeza del partido. con el debre la anotacion en anterior incurrirán en una multa que cuenta de su retiro hácia el nuevo luno baje de dos pesos ni exceda de gar de sudomicilio. diez
Art. 49. Formado el Registro, la Municipalidad lo hara pnblicar dando tambien publicidaul al fin de rada año intermedio at las itteraciones o. urridas en eise periudo.

Art. 51. En lus quince dias siguientes à la publicacion del Registro, ó de las listas de alteracion, los Concejus recibirán las reclamaciones que cualquier vecino del distrito liciere y la resolucion que se dicte se harà constar en el Registro.

Las personas que procedan de oiro

FIgURA 2: REVERSO de LA PLANILLA DEL REgISTRO DE VECINDAD (1887) 


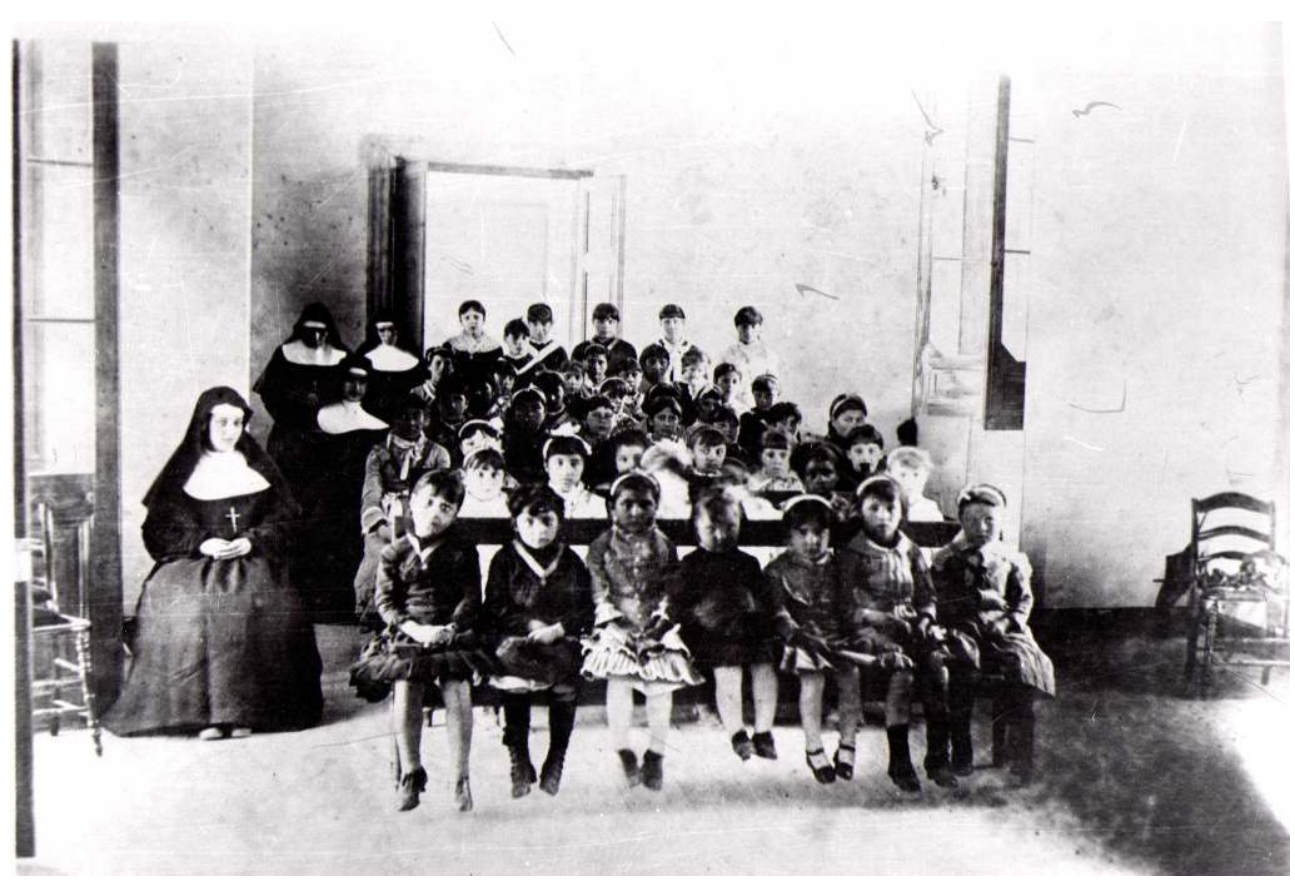

FIgURA 3: "COLEgIO DIRIgIDO POR HERMANAS DE CARIDAD EN PATAgONES. DIRECTORAS Y ALUMNAS DEL ESTABLECIMIENTO". ENCINA, MORENO Y CÍA., VISTAS FOTOgRÁfICAS DEL TERRITORIO DEL LIMAY Y NEUQUÉN, 1883.

\section{NOTES}

1. Cabe consignar que a la incuria de la mayoría de los organismos estatales respecto de su patrimonio documental, en los años de la última dictadura cívico militar, una orden de incineración de archivos comprometedores habría sido interpretada tan latamente por algunos jefes, que llevaron a la hoguera inclusive valiosos repositorios que por su antigüedad eran insospechables de detentar documentación "sensible". De modo tal que buena parte de lo rescatado por Emma Nozzi corresponde a aquellos años.

2. Los niños identificados en el libro de la Defensoría que no figuran en el Registro de Vecindad asignados a familias criollas son Malvina Perez, Manuela Rodríguez, Rufina Sinchel, Clemencia Dávila y Mercedes Molina (Libro I de la Defensoría de Menores, pp. 18, 38, 9 y 13-14).

3. Davies, G. (2009). Rescates o compras de indígenas en Carmen de Patagones. En: J. Farberman y S. Ratto (coords.), Historias mestizas en el Tucumán colonial y las pampas (siglos XVII-XIX). Buenos Aires: Editorial Biblos.

4. Archivo Histórico de la Provincia de Río Negro.

5. El niño "indio" Juan Araque de 9 años que no asiste a la escuela, por ejemplo, vive en la casa de Petrona Guerrero con cuatro huérfanos de apellido León, “argentinos", que sí lo hacen; en la casa de Domingo Pita hay seis niños que no son hijos suyos, cinco de los cuales están en edad escolar. Entre éstos, tres figuran como "argentino" y dos como "india". Los "argentinos" concurren a la escuela, pero no lo hacen María Pita de 13 y Florentina Sztyrle de 9, ambas "indias" que además no saben leer.

6. Puede llamar la atención la edad de cuatro años como inicio de la escolaridad. Para referenciarnos hemos tomado del Registro casos concretos de niños criollos que concurrían a la 
escuela con esa edad. Tales los casos de Teresa Abbate, Delfina Sánchez, hija del gerente del Banco Provincia, y Corina Crespo.

7. Entre estas familias destacadas a las que les han asignado niños indígenas se contaban la del intendente, comerciantes, hacendados, funcionarios de distintos organismos nacionales y provinciales, militares, etc.

8. Rómulo Sarmiento a Lino Roa, Viedma, octubre 13 de 1883. Museo Histórico Regional "Emma Nozzi", Caja Militar.

9. Museo Emma Nozzi: “Caja militar". Caja que contiene documentación militar "suelta”, es decir que no corresponde a Liborio Bernal ni a los tres copiadores de notas del Fuerte de Patagones que posee el archivo.

10. Emma Nozzi inició el Registro de Fuentes Orales del Museo en 1951, meses antes de fundar el museo.

\section{ABSTRACTS}

This paper includes the first results of an investigation undertaken by historians working at the Regional Historical Museum "Emma Nozzi" (MHREN), which aims to analyze the Registro de Vecindad [Neighbourhood Record] from Carmen de Patagones, conducted in 1887 according to 1876 law for Buenos Aires municipalities. By working with this and other documents, we discuss aspects of the capture and distribution of indigenous children among Carmen de Patagones families, since the campaigns of national expansion of 1870 and 1880 decades.

Se presentan en este artículo los primeros resultados de una investigación que realizan los historiadores del Museo Histórico Regional “Emma Nozzi” (MHREN), la que tiene por objeto analizar el Registro de Vecindad del partido de Carmen Patagones, levantado en 1887 conforme a la ley orgánica de las municipalidades bonaerenses de 1876. Mediante el trabajo con esta y otra documentación complementaria se comentan aspectos del proceso de captura y distribución de niños indígenas entre las familias de Carmen de Patagones, a partir de las campañas de expansión nacional de las décadas de 1870 y 1880.

\section{INDEX}

Keywords: Key words: National territories, population, indigenous, children

Palabras claves: Palabras clave: Territorios Nacionales, población, indígenas, infancia

\section{AUTHORS}

JORGE A. BUSTOS, 
LEONARDO A. DAM

Museo Histórico Regional “Emma Nozzi” del Banco de la Provincia de Buenos Aires.

Correo electrónico: museoema@live.com.ar 